\title{
Autonomic dysfunction is related to impaired pancreatic $\beta$ cell function in patients with coronary artery disease
}

\author{
J W Sayer, B Marchant, S V Gelding, J A Cooper, A D Timmis
}

\begin{abstract}
Objective-To assess the role of $\beta$ cell failure in the development of autonomic dysfunction in patients with coronary artery disease.

Design-Autonomic function was measured by standard clinical methods and by heart rate variability in 24 type II diabetic and 24 non-diabetic subjects with coronary artery disease. Quantitative estimates of pancreatic $\beta$ cell function $(\% \beta)$ and insulin resistance were made from basal plasma glucose and insulin concentrations using a computer solved model. Fasting proinsulin levels provided an independent measure of $\beta$ cell function.

Results-The circadian rhythm of sympathovagal balance (ratio of low to high frequency spectral components of heart rate variability) was significantly attenuated in patients with below median $(\% \beta \leqslant 63.3)$ compared with above median pancreatic $\beta$ cell function. Multiple measures of autonomic function showed positive associations with $\% \beta$ (low frequency: $r=0.41, \mathrm{p}=0.004$; high frequency: $r=0.27, \mathrm{p}=0.07$; lying/standing fall in systolic pressure: $r=-0.30, \mathrm{p}=0.04$ ) and negative associations with proinsulin (low frequency: $r=-0.35, \mathrm{p}=0.03$; high frequency: $r=-0.36, \mathrm{p}=0.02$; standard deviation of $\mathrm{RR}$ intervals: $r=-0.43, \mathrm{p}=0.007)$. Associations tended to be stronger in non-diabetic than diabetic patients. In contrast, there was no association between insulin resistance and either autonomic function or the circadian rhythm of sympathovagal balance, regardless of diabetes status.
\end{abstract}

Conclusions-The data are consistent with the hypothesis that $\beta$ cell failure plays a pathogenic role in the development of autonomic dysfunction in patients with coronary artery disease.

(Heart 2000;83:210-216)

Keywords: ischaemic heart disease; autonomic nervous system; $\beta$ cell function; diabetes mellitus

Diabetes is a major risk factor for atherosclerosis ${ }^{12}$ and is commonly complicated by autonomic dysfunction. This may interact with the clinical manifestations of coronary heart disease, particularly the perception of ischaemic cardiac pain, ${ }^{3}$ predisposing diabetic patients to silent myocardial ischaemia ${ }^{45}$ and painless infarction. ${ }^{6}$ Autonomic dysfunction may also have a direct impact on the pathogenesis and prognosis of myocardial infarction. Thus circadian variability in the onset of myocardial infarction (peaking in the morning) is diminished or absent in patients taking $\beta$ blockers, and also in diabetic patients, ${ }^{7-11}$ a group in whom autonomic dysfunction causes reductions in heart rate variability and abnormal circadian patterns of sympathovagal activity. ${ }^{12}{ }^{13}$ Similar abnormalities of heart rate variability after myocardial infarction identify a group at increased risk of death during early follow up. ${ }^{14-18}$

Mechanisms of autonomic dysfunction in diabetes are unknown. One hypothesis is that there is direct neurological damage resulting from the high circulating insulin levels that often accompany type II diabetes. Certainly, hyperinsulinaemia in type II diabetes has been associated with both autonomic dysfunction ${ }^{19}$ and increased cardiovascular morbidity and mortality. ${ }^{20-22}$ However, recently developed specific insulin assays have cast doubt upon this hypothesis, showing that patients with type II diabetes may be insulin deficient, the increase in circulating immunoreactive insulin reflecting cross reaction with proinsulin and its conversion metabolites. ${ }^{23}$ In patients with type II diabetes there is a disproportionate increase in circulating proinsulin which may reflect the increased demand on the pancreatic $\beta$ cell, causing depletion of mature insulin granules with premature release of unprocessed proinsulin. ${ }^{25}$ Raised proinsulin is thus regarded as a marker of pancreatic $\beta$ cell failure, and its positive correlation with sympathovagal balance led Töyry et al to speculate that proinsulin rather than insulin might have a role in the development of autonomic nervous damage. ${ }^{26}$ Another hypothetical mechanism of autonomic dysfunction in diabetes is ischaemic neurological damage occurring as an indirect response to insulin resistance, ${ }^{19} 27$ which has been shown to disturb the microcirculation in many tissues. $^{28} 29$

In the present study we examined potential mechanisms of autonomic nervous damage by measuring relations between autonomic function and the production and action of insulin in diabetic and non-diabetic patients with coronary artery disease.

\section{Methods}

Forty eight male patients aged 33 to 75 , with angiographically confirmed coronary artery disease, were recruited. All were either asymptomatic or had mild stable angina (Canadian Cardiovascular Society class I-II), with well 
preserved left ventricular function (ejection fraction $\geqslant 50 \%$ ). Twenty four patients had type II diabetes (mean (SD) duration 8.2 (9.5) years, 18 on oral hypoglycaemic agents and six on diet alone); none had a history of postural hypotension or other microvascular complications. The diabetic and non-diabetic patients were matched for ethnic origin, with Asians comprising half of each group. Exclusion criteria included previous myocardial infarction, hypertension, heart failure, revascularisation within the previous six months, atrial fibrillation, unstable or insulin dependent diabetes mellitus, clinical signs of peripheral neuropathy or other neurological disease, history of alcohol abuse, thyroid dysfunction, renal or hepatic dysfunction, retinopathy severe enough to warrant treatment, proteinuria, and concurrent treatment with angiotensin converting enzyme inhibitors. The study was approved by the East London and City Health Authority research ethics committee, and all patients gave written informed consent.

All vasoactive drugs ( $\beta$ blockers, long acting nitrates, and calcium antagonists) were stopped for at least three days before 24 hour Holter monitoring for heart rate variability. Oral hypoglycaemic agents were stopped for 24 hours and after a 12 hour overnight fast patients underwent blood sampling for insulin, proinsulin, glucose, and lipid determinations. Those patients without a previous diagnosis of diabetes underwent an oral glucose tolerance test according to World Health Organisation guidelines, ${ }^{30}$ using a $75 \mathrm{~g}$ glucose load to exclude diabetes or glucose intolerance. All patients returned one to two weeks later for a further fasting glucose, insulin, and proinsulin measurement, again having stopped oral hypoglycaemic agents for 24 hours. Clinical tests of autonomic function were

Table 1 Clinical characteristics of all patients according to diabetes status

\begin{tabular}{llll}
\hline & $\begin{array}{l}\text { All patients } \\
(n=48)\end{array}$ & $\begin{array}{l}\text { Non-diabetic } \\
(n=24)\end{array}$ & $\begin{array}{l}\text { Diabetic } \\
(n=24)\end{array}$ \\
\hline Age (years) & $58.0(8.71)$ & $56.3(9.87)$ & $59.7(7.19)$ \\
BMI $\left(\mathrm{kg} / \mathrm{m}^{2}\right)$ & $27.0(3.93)$ & $26.8(4.26)$ & $27.2(3.64)$ \\
SBP $(\mathrm{mm} \mathrm{Hg})$ & $127(20.3)$ & $122(15.8)$ & $133(23.2)$ \\
DBP $(\mathrm{mm} \mathrm{Hg})$ & $75.0(10.7)$ & $74.0(11.6)$ & $75.9(9.97)$ \\
Creatinine $(\mu \mathrm{mol} / \mathrm{l})$ & $109(17.3)$ & $106(15.8)$ & $112(18.5)$ \\
Total cholesterol $(\mathrm{mmol} / \mathrm{l})$ & $5.39(1.12)$ & $5.45(1.22)$ & $5.34(1.06)$ \\
Triglycerides $(\mathrm{mmol} / \mathrm{l})$ & $2.31(1.11)$ & $2.07(0.81)$ & $2.50(1.29)$ \\
Previous CABG/PTCA (n) & 18 & 8 & 10 \\
Smokers (n) & 10 & 3 & 7 \\
Waist/hip ratio & $0.989(0.035)$ & $0.977(0.038)$ & $1.001(0.028)^{\star}$ \\
\hline
\end{tabular}

Values are mean (SD).

$\star_{\mathrm{p}}=0.018 v$ non-diabetic patients.

BMI, body mass index; CABG, coronary artery bypass graft; DBP, diastolic blood pressure;

PTCA, percutaneous transluminal coronary angioplasty; SBP, systolic blood pressure.

Table 2 Metabolic characteristics of all patients and according to diabetes status

\begin{tabular}{llll}
\hline Homeostatic measure & $\begin{array}{l}\text { All patients } \\
(n=48)\end{array}$ & $\begin{array}{l}\text { Non-diabetic } \\
(n=24)\end{array}$ & $\begin{array}{l}\text { Diabetic } \\
(n=24)\end{array}$ \\
\hline Fasting glucose $(\mathrm{mmol} / \mathrm{l})$ & $7.81(3.230$ & $5.78(1.17)$ & $9.83(3.37)^{\star}$ \\
Fasting insulin $(\mathrm{pmol} / \mathrm{l})$ & $70.4(44.6)$ & $74.9(46.6)$ & $65.8(43.1)$ \\
Fasting proinsulin $(\mathrm{pmol} / \mathrm{l}) \ddagger$ & $11.5(8.06)$ & $8.17(3.60)$ & $14.3(9.62) \dagger$ \\
$\% \beta$ & $72.7(47.2)$ & $101(43.4)$ & $44.2(31.1)^{\star}$ \\
$\% \mathrm{~S}$ & $89.1(67.4)$ & $88.2(53.8)$ & $90.0(80.0)$ \\
\hline
\end{tabular}

Values are mean $(\mathrm{SD})$

${ }^{\star} \mathrm{p}<0.001, \mathrm{tp}=0.018$, diabetic $v$ non-diabetic patients; $\ddagger$ measured in only 40 patients (18 nondiabetic and 22 diabetic).

$\% \beta$, quantitative estimate of pancreatic $\beta$ cell function; $\% \mathrm{~S}$, inverse measure of insulin resistance. performed on all patients between 9.00 am and 12.00 noon. The waist-hip ratio was determined using the maximum waist and minimum hip measurements.

\section{HEART RATE VARIABILITY}

Twenty four hour ambulatory Holter monitoring for heart rate variability was performed using a Marquette Series 8000 recorder (Marquette-Hellige, Daventry, Northants, UK). Tapes were analysed by a single physician blinded to the identity of the patient. The recordings were analysed for spectral and nonspectral measures of heart rate variability with Marquette heart rate variability software. The measures calculated were: 24 hour mean amplitude of low $(0.04-0.15 \mathrm{~Hz})$ and high $(0.15-0.40 \mathrm{~Hz})$ frequency spectral analysis, proportion of adjacent $\mathrm{RR}$ intervals more than $50 \mathrm{~ms}$ different ( $\mathrm{pNN} 50$ ), root mean square of difference of successive RR intervals (rMSSD), mean of all five minute standard deviations of $\mathrm{RR}$ intervals (SD), standard deviation of five minute mean RR intervals (SDANN), and the standard deviation of all RR intervals (SDNN). The ratio of low to high frequency spectral components of heart rate variability was calculated and plotted at hourly intervals to provide information about the circadian rhythm of sympathovagal balance.

\section{CLINICAL AUTONOMIC FUNCTION TESTS}

Five standard tests of autonomic function were performed according to the methods of Ewing and Clarke. ${ }^{31} \mathrm{RR}$ intervals were calculated electronically from an ECG obtained with a signal amplifier, using custom written software (RR Medical Electronics, Birmingham, UK). A Valsalva manoeuvre (to $40 \mathrm{~mm} \mathrm{Hg}$ measured against a mercury column) was performed for 15 seconds and the Valsalva ratio was calculated from the ratio of the longest $R R$ interval after the manoeuvre to the shortest RR interval during the manoeuvre; a mean of three measures was used and provided an index of parasympathetic function. Heart rate was also monitored during deep breathing for six cycles for calculation of peak inspiratory and minimal expiratory RR values, the mean of the differences providing another index of parasympathetic function. Heart rate and blood pressure responses to standing from the supine position were measured. The heart rate ratio 30 beats after standing to 15 beats after standing (30:15 ratio) provided an index of parasympathetic function, and the absolute decrease in systolic pressure provided an index of sympathetic function. Finally the diastolic blood pressure response to sustained hand grip (at 30\% maximum) for as long as possible up to five minutes was determined as a measure of sympathetic function.

\section{LABORATORY ANALYSES}

Samples for glucose, insulin, proinsulin, and lipid determinations were taken in the fasted state on two occasions at least one week apart and in each case the mean value of these was used. Blood samples for plasma insulin and proinsulin assay were collected into prechilled 
Table 3 Autonomic function tests of all patients and by diabetes status

\begin{tabular}{|c|c|c|c|c|}
\hline & $\begin{array}{l}\text { All patients } \\
(n=48)\end{array}$ & $\begin{array}{l}\text { Non-diabetic } \\
(n=24)\end{array}$ & $\begin{array}{l}\text { Diabetic } \\
(n=24)\end{array}$ & p Value * \\
\hline \multicolumn{5}{|l|}{ Clinical tests } \\
\hline Valsalva ratio & $1.38(0.20)$ & $1.45(0.20)$ & $1.311(0.16)$ & 0.010 \\
\hline Respiratory variation (beats/min) & $12.0(6.48)$ & $13.1(7.35)$ & $10.9(5.42)$ & NS \\
\hline $30: 15$ heart rate ratio & $1.12(0.13)$ & $1.17(0.15)$ & $1.071(0.081)$ & 0.007 \\
\hline Supine/standing fall in systolic pressure $(\mathrm{mm} \mathrm{Hg})$ & $-1.40(7.19)$ & $-3.13(6.15)$ & $0.33(7.84)$ & NS \\
\hline Increase in diastolic pressure on handgrip $(\mathrm{mm} \mathrm{Hg})$ & $18.1(6.34)$ & $20.9(10.4)$ & $(15.3(7.88)$ & 0.042 \\
\hline \multicolumn{5}{|l|}{ Heart rate variability } \\
\hline $\operatorname{LF}\left(\operatorname{In}\left(\mathrm{ms}^{2}\right)\right)$ & $5.802(0.788)$ & $6.05(0.810$ & $5.55(0.70)$ & 0.025 \\
\hline $\mathrm{HF}\left(\operatorname{In}\left(\mathrm{ms}^{2}\right)\right)$ & $4.446(0.895)$ & $4.62(0.92)$ & $4.27(0.85)$ & NS \\
\hline SDANN (ms) & $109(32.1)$ & $116(36.8)$ & $102(25.5)$ & NS \\
\hline $\mathrm{SD}(\mathrm{ms})$ & $49.9(16.3)$ & $54.7(18.1)$ & $45.1(12.9)$ & 0.04 \\
\hline $\mathrm{rMSSD}(\mathrm{ms})$ & $26.0(11.4)$ & $27.6(11.3)$ & $24.5(11.5)$ & NS \\
\hline pMN50 (\%) & $6.79(7.67)$ & $7.57(7.64)$ & $6.00(7.78)$ & NS \\
\hline SDNN (ms) & $122(33.5)$ & $130(37.8)$ & $114(27.0)$ & NS \\
\hline
\end{tabular}

Values are mean (SD)

*Diabetic $v$ non-diabetic patients.

$\mathrm{HF}$, high frequency; LF, low frequency; pNN50, proportion of adjacent RR intervals more than $50 \mathrm{~ms}$ different; rMSSD, root mean square of difference of successive RR intervals; SD, mean of all five minute standard deviations of RR intervals; SDANN, standard deviation of five minute RR intervals; SDNN, standard deviation of all RR intervals from the mean.

tubes containing heparin, centrifuged immediately at $2500 \times g$ at $4^{\circ} \mathrm{C}$, and stored without delay at $-400^{\circ} \mathrm{C}$ until analysed. Samples for venous plasma glucose were collected simultaneously into fluoride oxalate tubes and samples for lipids into plain tubes.

Plasma glucose was measured by a glucose oxidase method using a centrifugal analyser (Cobas Bio/Roche, Ely, UK). Plasma insulin was analysed using a specific enzyme linked immunosorbent assay method (Dako Insulin, Dako Diagnostics, Ely, Cambridgeshire, UK) which does not cross react with proinsulin. The detection limit was $3 \mathrm{pmol} / 1$ and the interassay coefficient of variation less than $10 \%$ between 40 and $1250 \mathrm{pmol} / 1$. Plasma proinsulin was analysed by a two site immunometric assay (Dako Proinsulin, Dako Diagnostics) with a detection limit of $1.0 \mathrm{pmol} / 1$ and interassay coefficient of variation less than $12 \%$ between 4.6 and $55 \mathrm{pmol} / 1$. Plasma total cholesterol and triglyceride were measured enzymatically.

INSULIN RESISTANCE AND $\beta$ CELL FUNCTION Pancreatic $\beta$ cell function and insulin sensitivity were measured using the homeostatic model assessment (HOMA) method. ${ }^{32}$ This method uses a computer solved model which predicts basal plasma glucose and insulin concentrations arising from varying degrees of pancreatic $\beta$ cell deficiency and insulin resistance. Thus comparison of fasting glucose and insulin values with the model's predictions allowed a quantitative assessment of the contributions of insulin sensitivity $(\% \mathrm{~S}$, an inverse measure of insulin resistance) and pancreatic $\beta$ cell dysfunction $(\% \beta)$ to the fasting glucose concentration.

STATISTICAL ANALYSIS

Statistical analyses were performed using the computer program Statistica for Windows, Release 5.1 (Statsoft Inc, Tulsa, Oklahoma, USA). Data are presented as mean (SD) unless otherwise stated. Comparison between diabetic and non-diabetic patients was by unpaired $t$ test for normally distributed data and by the MannWhitney $U$ test for data that were not normally distributed $(\% \beta, \% \mathrm{~S}$, insulin, proinsulin, rMSSD, and $\mathrm{pMN} 50)$. Both autonomic function and pancreatic $\beta$ cell function were negatively correlated with age; age adjusted variables were derived using estimates derived from regression equations fitted overall and within subgroups. Variables were log transformed before regression where appropriate. Associations between age adjusted autonomic function and variables derived from fasting glucose and insulin measurements were assessed by calculating Spearman's rank correlation $\left(r_{\mathrm{s}}\right)$.

Table 4 Age adjusted correlation of autonomic function with homeostatic function in all patients

\begin{tabular}{|c|c|c|c|c|c|c|}
\hline & \multicolumn{2}{|l|}{$\% \beta$} & \multicolumn{2}{|l|}{$\% S$} & \multicolumn{2}{|c|}{ Proinsulin } \\
\hline & $r_{s}$ & $p$ Value & $r_{s}$ & p Value & $r_{s}$ & $p$ Value \\
\hline \multicolumn{7}{|l|}{ Spectral measures of heart rate variability } \\
\hline LF & 0.41 & 0.004 & -0.01 & 0.95 & -0.35 & 0.03 \\
\hline $\mathrm{HF}$ & 0.27 & 0.07 & -0.09 & 0.56 & -0.36 & 0.02 \\
\hline \multicolumn{7}{|l|}{ Non-spectral measures of heart rate variability } \\
\hline SDANN & 0.20 & 0.18 & 0.21 & 0.15 & -0.42 & 0.007 \\
\hline SD & 0.29 & 0.04 & 0.08 & 0.60 & -0.36 & 0.03 \\
\hline rMSSD & 0.17 & 0.24 & -0.07 & 0.65 & -0.31 & 0.05 \\
\hline $\mathrm{pMN} 50$ & 0.14 & 0.33 & -0.07 & 0.65 & -0.26 & 0.11 \\
\hline SDNN & 0.20 & 0.17 & 0.24 & 0.10 & -0.43 & 0.007 \\
\hline \multicolumn{7}{|l|}{ Clinical tests } \\
\hline Valsalva ratio & 0.03 & 0.82 & -0.02 & 0.89 & -0.05 & 0.78 \\
\hline Respiratory variation (beats/min) & 0.06 & 0.70 & -0.15 & 0.31 & -0.09 & 0.59 \\
\hline $30: 15$ heart rate ratio & 0.17 & 0.25 & 0.18 & 0.22 & -0.22 & 0.17 \\
\hline Supine/standing fall in systolic pressure ( $\mathrm{mm} \mathrm{Hg}$ ) & -0.30 & 0.04 & 0.07 & 0.64 & -0.09 & 0.59 \\
\hline Increase in diastolic pressure; handgrip $(\mathrm{mm} \mathrm{Hg})$ & 0.18 & 0.22 & 0.12 & 0.40 & -0.17 & 0.29 \\
\hline
\end{tabular}

HF, high frequency; LF, low frequency; pNN50, proportion of adjacent RR intervals more than $50 \mathrm{~ms}$ different; rMSSD, root mean square of difference of successive RR intervals; $r$, Spearman correlation coefficient; SD, mean of all five minute standard deviations of RR intervals; SDANN, standard deviation of five minute RR intervals; SDNN, standard deviation of all RR intervals from the mean. 
Table 5 Age adjusted correlations of autonomic function with homeostatic function by diabetes status

\begin{tabular}{|c|c|c|c|c|c|c|c|c|c|c|c|c|}
\hline & \multicolumn{6}{|c|}{ Non-diabetic } & \multicolumn{6}{|c|}{ Diabetic } \\
\hline & \multicolumn{2}{|l|}{$\% \beta$} & \multicolumn{2}{|l|}{$\% S$} & \multicolumn{2}{|c|}{ Proinsulin } & \multicolumn{2}{|l|}{$\% \beta$} & \multicolumn{2}{|l|}{$\% S$} & \multicolumn{2}{|c|}{ Proinsulin } \\
\hline & $r_{s}$ & $p$ Value & $r_{s}$ & $p$ Value & $r_{s}$ & $p$ Value & $r_{s}$ & $p$ Value & $r_{s}$ & $p$ Value & $r_{s}$ & p Value \\
\hline \multicolumn{13}{|l|}{ Spectral measures of heart rate variability } \\
\hline LF & 0.31 & 0.14 & -0.15 & 0.48 & -0.29 & 0.25 & 0.10 & 0.64 & 0.27 & 0.20 & -0.23 & 0.29 \\
\hline $\mathrm{HF}$ & 0.46 & 0.02 & -0.29 & 0.18 & -0.29 & 0.26 & -0.10 & 0.64 & 0.14 & 0.53 & -0.25 & 0.26 \\
\hline \multicolumn{13}{|l|}{ Non-spectral measures of heart rate variability } \\
\hline SDANN & 0.20 & 0.35 & -0.12 & 0.56 & -0.45 & 0.06 & -0.29 & 0.18 & 0.45 & 0.03 & -0.14 & 0.51 \\
\hline $\mathrm{SD}$ & 0.19 & 0.37 & -0.08 & 0.70 & -0.38 & 0.12 & -0.08 & 0.71 & 0.33 & 0.12 & -0.21 & 0.34 \\
\hline rMSSD & 0.31 & 0.14 & -0.23 & 0.29 & -0.27 & 0.28 & -0.20 & 0.35 & 0.17 & 0.43 & -0.12 & 0.58 \\
\hline $\mathrm{pMN} 50$ & 0.39 & 0.06 & -0.24 & 0.25 & -0.29 & 0.25 & -0.15 & 0.48 & 0.14 & 0.52 & -0.09 & 0.69 \\
\hline SDNN & 0.17 & 0.42 & -0.08 & 0.70 & -0.46 & 0.06 & -0.24 & 0.26 & 0.48 & 0.02 & -0.21 & 0.36 \\
\hline \multicolumn{13}{|l|}{ Clinical tests } \\
\hline Valsalva ratio & 0.03 & 0.90 & -0.11 & 0.62 & 0.24 & 0.33 & -0.45 & 0.03 & 0.10 & 0.63 & -0.07 & 0.74 \\
\hline Respiratory variation (beats/min) & -0.24 & 0.26 & -0.09 & 0.67 & 0.14 & 0.58 & -0.06 & 0.77 & -0.07 & 0.75 & -0.10 & 0.67 \\
\hline $30: 15$ heart rate ratio & -0.24 & 0.25 & -0.02 & 0.93 & 0.14 & 0.59 & -0.18 & 0.39 & 0.46 & 0.02 & -0.21 & 0.34 \\
\hline Supine/standing fall in systolic pressure $(\mathrm{mm} \mathrm{Hg})$ & -0.13 & 0.55 & -0.07 & 0.76 & -0.20 & 0.44 & -0.18 & 0.40 & 0.19 & 0.38 & -0.23 & 0.32 \\
\hline Increase in diastolic pressure; handgrip $(\mathrm{mm} \mathrm{Hg})$ & -0.05 & 0.83 & 0.27 & 0.19 & -0.28 & 0.25 & -0.21 & 0.33 & 0.13 & 0.53 & 0.02 & 0.93 \\
\hline
\end{tabular}

HF, high frequency; LF, low frequency; pNN50, proportion of adjacent RR intervals more than 50 ms different; rMSSD, root mean square of difference of successive RR intervals; $r_{s}$, Spearman correlation coefficient; SD, mean of all five minute standard deviations of RR intervals; SDANN, standard deviation of five minute RR intervals; SDNN, standard deviation of all RR intervals from the mean.

\section{Results}

CLINICAL CHARACTERISTICS

There were no significant differences between the diabetic and non-diabetic patients as regards age, sex, blood pressure, smoking status, renal function, and fasting lipids (table 1). Body mass index was similar for the two groups, but the waist-hip ratio tended to be higher in diabetic than in non-diabetic patients.

\section{$\beta$ CELL FUNCTION AND INSULIN SENSITIVITY}

Diabetic patients had higher fasting glucose and proinsulin levels than non-diabetic patients, and pancreatic $\beta$ cell function $(\% \beta)$ was reduced (table 2). However, fasting insulin levels and insulin sensitivity $(\% \mathrm{~S})$ were not significantly different between the two groups.
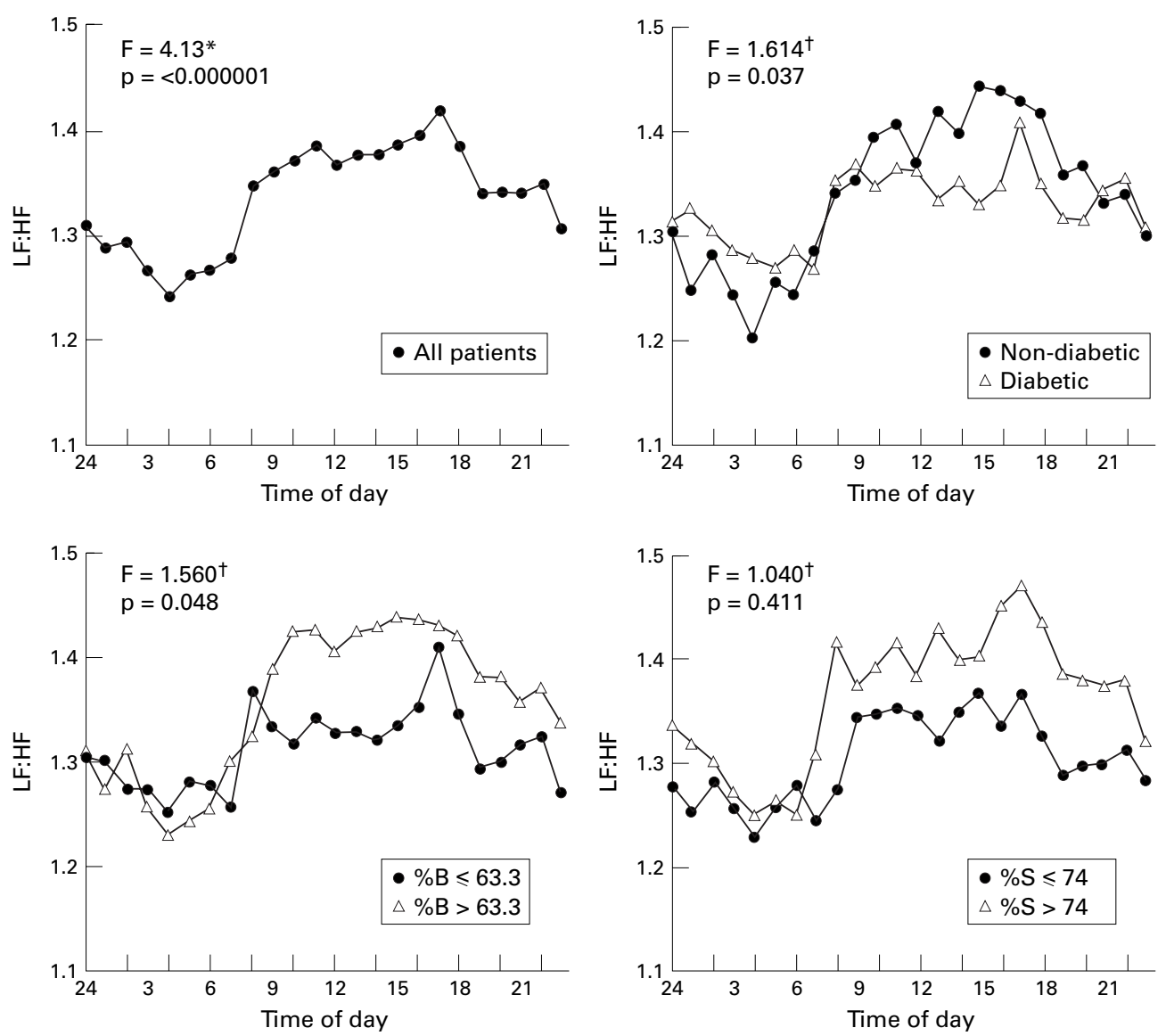

Figure 1 Circadian variation of sympathovagal balance for the entire cohort and by diabetic status, pancreatic $\beta$ cell function $(\% \beta)$, and insulin resistance $(\% S)$. LH:HF represents the low to high frequency ratio. Values of $\% \beta$ and $\% S$ have been divided into those above and below the median $(63.3 \%$ and $74.0 \%$, respectively). *Variation over time; †between group comparison. 
AUTONOMIC FUNCTION

Autonomic function, whether tested clinically or by heart rate variability, showed a consistent tendency to be more abnormal in the diabetic than the non-diabetic patients (table 3). Among the clinical tests, differences were significant for Valsalva ratio, lying/standing heart rate ratio, and increase in diastolic pressure on handgrip. Among the measures of heart rate variability, differences were significant for low frequency spectral analysis and standard deviation of RR intervals.

RELATION BETWEEN AUTONOMIC FUNCTION AND MEASURES OF PANCREATIC $\beta$ CELL FUNCTION (\% $\beta$ AND PROINSULIN) AND INSULIN RESISTANCE (\%s)

These results are shown in tables 4 and 5 . Analysis of the entire cohort revealed no correlation between autonomic function and insulin sensitivity $(\% \mathrm{~S})$, regardless of diabetes status. In contrast, multiple measures of autonomic function correlated positively with pancreatic $\beta$ cell function $(\% \beta)$ and negatively with fasting proinsulin levels. Subgroup analysis showed that these correlations tended to be stronger in non-diabetic than diabetic patients.

CIRCADIAN VARIABILITY OF SYMPATHOVAGAL

ACTIVITY

Analysis of sympathovagal balance (measured by the ratio of low to high frequency spectral components of heart rate variability) within the entire cohort showed significant circadian variation ( $p<0.0001)$ with a nocturnal trough rising abruptly around 6.00 am (fig 1). Circadian variation was significantly attenuated in diabetic compared with non-diabetic patients, and in patients with below median $(\% \beta \leqslant 63.3)$ compared with above median pancreatic $\beta$ cell function. In contrast, the circadian variation of sympathovagal balance was unaffected by reductions of insulin sensitivity.

\section{Discussion}

This study has confirmed our previous observation that in stable patients with coronary artery disease, autonomic function measured clinically or by heart rate variability is reduced in patients with type II diabetes compared with non-diabetic controls. We have now extended this observation by showing that autonomic function is also reduced in patients with pancreatic $\beta$ cell dysfunction, regardless of diabetes status. Importantly, we found no association between autonomic function and insulin resistance, measured by the HOMA model.

AUTONOMIC DYSFUNCTION AND TYPE II DIABETES Evaluation of autonomic function used not only the "bedside" techniques of Ewing and Clarke, ${ }^{31}$ but also measures of heart rate variability that are particularly sensitive for detecting early neuropathy in diabetes. ${ }^{33} 34$ Despite the fact that patients with and without type II diabetes were similar in age and none had neuropathic symptoms or evidence of other microvascular complications, there was a consistent trend toward autonomic impairment in the patients with type II diabetes compared with non-diabetic controls. This is consistent with our previous observations in type II diabetic patients with coronary artery disease $^{5}$ and confirms that subclinical autonomic neuropathy is common in this group, predisposing to silent ischaemia and painless infarction.

We have previously hypothesised that predisposition to acute ischaemic events in diabetic patients with coronary artery disease is favoured by abnormal circadian rhythms of autonomic function. ${ }^{11}$ In the present study, circadian rhythms of autonomic function were plotted using spectral analysis of heart rate variability to provide information about sympathovagal balance, according to the method of Pagani et al..$^{35}$ For the group as a whole, the normal pattern of nocturnal trough and morning surge of sympathovagal balance was demonstrated, but in the diabetic group, the rhythm was significantly attenuated compared with the non-diabetic group, indicating that the neuropathic defect that characterises type 2 diabetic patients with coronary artery disease may have potentially important physiological consequences.

AUTONOMIC DYSFUNCTION AND PANCREATIC $\beta$ CELL FAILURE

Despite its clinical importance in coronary artery disease, the cause of autonomic neuropathy in patients with type II diabetes is not known. Töyry et $a l^{26}$ have recently hypothesised that proinsulin, a marker of pancreatic $\beta$ cell failure, ${ }^{25} 36$ may have a direct pathogenic role based on its negative association with sympathovagal balance, a finding we have confirmed in the present study. Although the associations in both studies were weak, the consistency of the finding must strengthen its validity. We have now extended these observations by quantitative estimation of pancreatic $\beta$ cell function derived from fasting plasma glucose and insulin values using the method of homeostasis model assessment (HOMA). ${ }^{32}$ HOMA estimates of $\beta$ cell function have been well validated ${ }^{32}$ and in the present study were significantly associated with heart rate variability measurements of autonomic function. Moreover, the circadian variation of sympathovagal balance was significantly attenuated in the group with $\beta$ cell dysfunction, regardless of diabetes status, further strengthening the hypothesis that $\beta$ cell dysfunction is related to the development of autonomic neuropathy, probably because of increased proinsulin production. Of course, this need not imply a causal relation. Thus, while it is tempting to speculate that increased proinsulin production in response to $\beta$ cell dysfunction plays a pathogenic role in diabetic autonomic neuropathy, there is no collateral evidence to support this hypothesis. The converse hypothesis is that autonomic dysfunction affects pancreatic $\beta$ cell failure, as the autonomic nervous system regulates insulin secretion from $\beta$ cells and impaired processing of insulin may result in high circulating levels of 
proinsulin. However, this hypothesis is less likely given that the increase in circulating immunoreactive insulin (incorporating insulin, proinsulin, and its conversion intermediates) that accompanies $\beta$ cell failure in patients with type II diabetes has been shown to predict future development of autonomic neuropathy, ${ }^{19}$ and the present results do support an involvement of proinsulin levels in the pathogenesis of autonomic dysfunction. In this study we measured intact proinsulin. The relative contribution of the proinsulin conversion intermediates to the observed relation with autonomic function is unknown but the major intermediate conversion product 32,33 split proinsulin may be implicated in view of the observation that plasma 32,33 split proinsulin concentrations are more closely related to cardiovascular risk factors than insulin or intact proinsulin in both diabetic and nondiabetic subjects. $^{3738}$

We have previously found that the altered perception of angina sometimes associated with autonomic dysfunction can be demonstrated in non-diabetic as well as in diabetic patients with coronary artery disease. ${ }^{3}$ Similarly, the association between autonomic and pancreatic $\beta$ cell dysfunction in the present study occurred in both diabetic and nondiabetic patients. This suggests that early $\beta$ cell failure may predispose to neuropathy even in the absence of frank diabetes or impaired glucose tolerance, both of which had been excluded in the non-diabetic group by glucose tolerance testing.

\section{AUTONOMIC DYSFUNCTION AND INSULIN}

RESISTANCE

An important observation in the present study was the absence of any association between autonomic function and insulin resistance. Again, insulin resistance was derived from fasting plasma glucose and insulin levels using the HOMA method, ${ }^{32}$ which correlates well with the gold standard method for measuring insulin sensitivity, the euglycaemic hyperinsulinaemic clamp. ${ }^{32}$ None of the wide range of clinical and heart rate variability measurements of autonomic function obtained in this study showed significant association with insulin resistance; nor was there significant attenuation of the circadian variation of sympathovagal balance in the subgroup with heightened insulin resistance. The combined weight of these observations makes insulin resistance an unlikely player in the pathogenesis of autonomic neuropathy affecting type II diabetic patients with coronary artery disease.

CONCLUSIONS

We have found that pancreatic $\beta$ cell function, but not insulin resistance, is significantly associated with several measures of autonomic function. This association is largely independent of diabetic status. The data are consistent with the hypothesis that $\beta$ cell failure plays a pathogenic role in the development of autonomic dysfunction in patients with coronary artery disease.
1 Kannel WB, McGee DL. Diabetes and cardiovascular risk factors: the Framingham Study. Circulation 1979:59:813.

2 Donahue RP, Abbott RD, Bloom E, et al. Central obesity and coronary heart disease in men. Lancet 1987;i:821-4.

3 Ambepityia G, Kopelman PG, Ingram D, et al. Exertional myocardial ischemia in diabetes: a quantitative analysis of anginal perceptual threshold and the influence of autonomic function. $\mathcal{F}$ Am Coll Cardiol 1990;15:72-7.

4 Langer A, Freeman MR, Josse RG, et al. Detection of silent myocardial ischemia in diabetes mellitus. Am $\mathcal{F}$ Cardiol 1991;67:1073-8.

5 Marchant B, Umachandran V, Stevenson R, et al. Silent myocardial ischaemia: role of subclinical neuropathy in patients with and without diabetes. 7 Am Coll Cardiol 1993; 22:1433-7.

6 Margolis JR, Kannel WB, Feinleib M, et al. Clinical features of unrecognized myocardial infarction-silent and symptomatic. Eighteen year follow-up: the Framingham Study. Am f Cardiol 1973;32:1-7.

7 Muller JE, Stone PE, Turi ZG, et al. Circadian variation in the frequency of onset of acute myocardial infarction. $N$ Engl F Med 1985;313:1315-22.

8 Hjalmarson Å, Gilpin EA, Nicod P, et al. Differing circadian patterns of symptom onset in subgroups of patients with acute myocardial infarction. Circulation 1989;80:267-75.

9 Tanaka T, Fujita M, Fudo T, et al. Modification of the circadian variation of symptom onset of acute myocardial infarction in diabetes mellitus. Coronary Art Dis 1995;6: 241-4.

10 Fava S, Azzopardi J, Muscat HA, et al. Absence of circadian variation in the onset of acute myocardial infarction in diabetic subjects. Br Heart $\mathcal{F}$ 1995; 74:370-2.

11 Sayer JW, Wilkinson P, Ranjadayalan K, et al. Attenuation or absence of circadian and seasonal rhythms of acute myocardial infarction. Br Heart F 1997;77:325-9.

12 Bernardi L, Ricordi L, Lozzari P, et al. Impaired circadian modulation of sympathovagal activity in diabetes. A possible explanation for altered temporal onset of cardiovascular disease. Circulation 1992;86:1443-52.

13 Zarich S, Waxman S, Freeman RT, et al. Effect of autonomic nervous system dysfunction on the circadian pattern of myocardial ischemia in diabetes mellitus. $\mathcal{F} \mathrm{Am}$ Coll Cardiol 1994;24:956-62.

14 Kleiger RE, Miller JP, Bigger JT, et al. Decreased heart rate variability and its association with increased mortality after acute myocardial infarction. Am f Cardiol 1987;59: 256-62.

15 Odemuyiwa O, Malik M, Farrell T, et al. Comparison of the predictive characteristics of heart rate variability index and left ventricular ejection fraction for all cause mortality, arrhythmic events and sudden death after acute myocardial infarction. Am 7 Cardiol 1991;68:434-9.

16 Bigger JTT, Fleiss JL, Steinman RC, et al. Frequency domain measures of heart period variability and mortality after myocardial infarction. Circulation 1992;85:164-71.

17 Bigger JT, Fleiss JL, Rolnitzky LM, et al. Frequency domain measures of heart period variability to assess risk late after myocardial infarction. $\mathcal{A}$ Am Coll Cardiol 1993;21:729-36.

8 Vaishnav S, Stevenson R, Marchant B, et al. The relation between heart rate variability early after acute myocardial infarction and long-term mortality. Am F Cardiol 1994;73: 653-7.

19 Töyry JP, Niskanen LK, Mäntysaari MJ, et al. Occurrence, predictors, and clinical significance of autonomic neuropathy in NIDDM: ten-year follow-up from the diagnosis. Diabetes 1996;45:308-15.

20 Despres J-P, Lamarche, Mauriege P, et al. Hyperinsulinemia as an independent risk factor for ischemic heart disease. $N$ as an independent risk factor

21 Pyörälä K. Relationship of glucose tolerance and plasma insulin to the incidence of coronary heart disease: results from two population studies in Finland. Diabetes Care 1979;2:131-41

22 Ducimetiere P, Eschwege E, Papoz L, et al. Relationship of plasma insulin levels to the incidence of myocardial infarction and coronary heart disease in a middle-aged population. Diabetologia 1980;19:205-10.

23 Temple RC, Clark P, Schneider A, et al. Insulin deficiency in non-insulin dependent diabetes. Lancet 1989;i:293-5.

24 Davies MJ, Metcalfe J, Gray IP, et al. Insulin deficiency rather than hyperinsulinaemia in newly diagnosed type 2 rather than hyperinsulinaemia in newly diagnosed

25 Ward WK, Lacava EC, Paquette TL, et al. Disproportionate elevation of immunoreactive proinsulin in type 2 (noninsulin-dependent) diabetes and in experimental insulin insulin-dependent) diabetes and in expe
resistance. Diabetologia 1987;30:698-702.

26 Töyry JP, Niskanen LK, Mäntysaari MJ, et al. Do high proinsulin and c-peptide levels play a role in autonomic nervous dysfunction? Power spectral analysis in patients with non-insulin-dependent diabetes and nondiabetic subjects. Circulation 1997;96:1185-91.

27 Cameron NE, Cotter MA. The relationship of vascular changes to metabolic factors in diabetes mellitus and their role in the development of peripheral nerve complications. Diabetes Metab Rev 1994;10:189-224.

28 Laasko M, Edelman SV, Brechtel G, et al. Decreased effect of insulin to stimulate skeletal muscle blood flow in obese man: a novel mechanism for insulin resistance. F Clin Invest 1990;85:1844-52.

29 Ganrot PO. Insulin resistance syndrome: possible key role of blood flow in resting muscle. Diabetologia 1993;36: $876-9$. 
30 WHO diabetes Mellitus Study group. Technical Report Series 729. Geneva: World Health Organisation, 1985:9-17.

31 Ewing DJ, Clarke BF. Diagnosis and management of diabetic autonomic neuropathy. BMF 1982;285 of diabeti

32 Matthews DR, Hosker JP, Rudenski AS. Homeostasis model assessment: insulin resistance and $\beta$ cell function from fasting plasma glucose and insulin concentrations in man. Diabetologia 1985;28:412-19.

33 Lishner M, Akselrod S, Avi M, et al. Spectral analysis of heart rate fluctuations. A non-invasive, sensitive method for the early diagnosis of autonomic neuropathy in diabetes mellitus. F Auton Nerv Syst 1987;19:119-25.

34 Malpas SC, Maling TJ. Heart-rate variability and cardiac autonomic function in diabetes. Diabetes 1990;39: $1177-8$
35 Pagani M, Mazzuero G, Ferrari A, et al. Sympathovagal interaction during mental stress. A study using spectral analysis of heart rate variability in healthy control subjects and patients with a prior myocardial infarction. Circulation 1991;83(suppl II):43-51.

36 Hales CN. The pathogenesis of NIDDM. Diabetologia 1994;37(suppl 2):S162-8.

37 Haffner SM, Mykkänen L, Stern MP, et al. Relationship of proinsulin and insulin to cardiovascular risk factors in nondiabetic subjects. Diabetes 1993;42:1297-302.

38 Nagi DK, Hendra TJ, Ryle AJ, et al. The relationship of concentrations of insulin, intact proinsulin and 32,33 split proinsulin with cardiovascular risk factors in type 2 (non-insulin-dependent) diabetic subjects. Diabetologia 1990;33:532-7.

\section{IMAGES IN CARDIOLOGY}

\section{ST segment elevation in the precordial leads mimicking Brugada syndrome}

A 58 year old man was referred following the diagnosis of recent onset inferior myocardial infarction (A). Coronary arteriography showed a critical stenosis in the proximal segment of the right coronary artery. Percutaneous transluminal coronary angioplasty (PTCA) was performed to dilate the stenotic lesion. During the first attempt at PTCA, ST segment elevation in leads II, III, aVF, and the precordial leads similar to ECG changes seen in Brugada syndrome were recognised (B). ST elevation was transiently observed during this procedure and thereafter it was not seen in spite of repeated PTCA (C). Although coronary arteriography revealed moderate stenosis in the right ventricular branch before PTCA, it was completely occluded at the end of the session. As the right ventricular branch originated from just before the proximal portion of the stenotic lesion of the right coronary artery, it was considered to be concomitantly exposed to ischaemia during PTCA.

The right ventricular free wall to the outflow tract are important regions in the cause of ST segment elevation similar to Brugada syndrome, regardless of whether the cause is ischaemic or idiopathic.

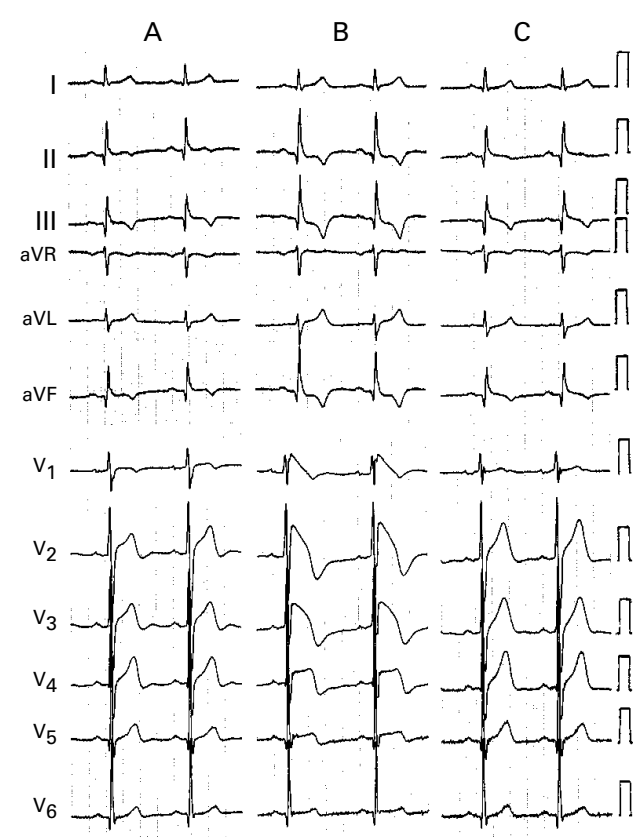

YUJI NAKAZATO TAKESHI KURATA HIROSHI YAMAGUCHI 